\title{
Prognostic Factors and Scoring System for Death from Visceral Leishmaniasis: An Historical Cohort Study in Brazil
}

\author{
Wendel Coura-Vital ${ }^{1,29}$, Valdelaine Etelvina Miranda de Araújo ${ }^{3,49}$, Ilka Afonso Reis ${ }^{5}$, \\ Frederico Figueiredo Amancio ${ }^{1,6}$, Alexandre Barbosa Reis ${ }^{2}$, Mariângela Carneiro ${ }^{1,4 *}$
}

1 Pós-graduação em Ciências da Saúde, Infectologia e Medicina Tropical, Faculdade de Medicina, Universidade Federal de Minas Gerais, Belo Horizonte, Minas Gerais, Brasil, 2 Núcleo de Pesquisas em Ciências Biológicas, Instituto de Ciências Exatas e Biológicas, Universidade Federal de Ouro Preto, Ouro Preto, Minas Gerais, Brasil, 3 Secretaria Municipal de Saúde, Prefeitura de Belo Horizonte, Belo Horizonte, Minas Gerais, Brasil, 4 Departamento de Parasitologia, Instituto de Ciências Biológicas, Universidade Federal de Minas Gerais, Belo Horizonte, Minas Gerais, Brasil, 5 Departamento de Estatística, Instituto de Ciências Exatas, Universidade Federal de Minas Gerais, Belo Horizonte, Minas Gerais, Brasil, 6 Fundação Hospitalar do Estado de Minas Gerais, Belo Horizonte, Minas Gerais, Brasil

\begin{abstract}
Background: In Brazil, case-fatality rates attributable to visceral leishmaniasis (VL) are high and knowledge of the risk factors associated with death may help reduce mortality. The aim of this study was to construct and validate a scoring system for prognosis of death from VL by using all cases reported in Brazil from 2007 to 2011.

Methodology: In this historical cohort study, 18,501 VL cases were analyzed; of these, 17,345 cases were cured and 1,156 cases caused death. The database was divided into two series: primary (two-thirds of cases), to develop the model score, and secondary (one-third of cases), to validate the scoring system. Multivariate logistic regression models were performed to identify factors associated with death from $V L$, and these were included in the scoring system.

Principal Findings: The factors associated with death from VL were: bleeding (score 3); splenomegaly (score 1); edema (score 1); weakness (score 1); jaundice (score 1); Leishmania-HIV co-infection (score 1); bacterial infection (score 1); and age ( $\leq 0.5$ years [score 5]; $>0.5$ and $\leq 1$ [score 2]; $>19$ and $\leq 50$ [score 2]; $>50$ and $<65$ [score 3]; $\geq 65$ [score 5 ]). It was observed that patients with a score of 4 had a probability of death of approximately $4.5 \%$ and had a worse prognosis. The sensitivity, specificity, and accuracy of this score were $89.4,51.2$, and 53.5 , respectively.

Conclusions/Significance: The scoring system based on risk factors for death showed good performance in identifying patients with signs of severity at the time of clinical suspicion of VL and can contribute to improving the surveillance system for reducing case fatalities. The classification of patients according to their prognosis for death may assist decision-making regarding the transfer of the patients to hospitals more capable of handling their condition, admission to the intensive care unit, and adequate support and specific treatment.
\end{abstract}

Citation: Coura-Vital W, Araújo VEMd, Reis IA, Amancio FF, Reis AB, et al. (2014) Prognostic Factors and Scoring System for Death from Visceral Leishmaniasis: An Historical Cohort Study in Brazil. PLoS Negl Trop Dis 8(12): e3374. doi:10.1371/journal.pntd.0003374

Editor: Helton da Costa Santiago, Universidade Federal de Minas Gerais, Brazil

Received June 10, 2014; Accepted October 28, 2014; Published December 11, 2014

Copyright: (c) 2014 Coura-Vital et al. This is an open-access article distributed under the terms of the Creative Commons Attribution License, which permits unrestricted use, distribution, and reproduction in any medium, provided the original author and source are credited.

Data Availability: The authors confirm that, for approved reasons, some access restrictions apply to the data underlying the findings. Data analyzed in the present study were registered in the Reportable Disease Information System (SINAN) and were provided by the Department of Health Surveillance of Brazilian Ministry of Health (SINAN/CIEVS/DEVEP/MS). This system provides a center for the collection and processing of data and helps the dissemination of information generated by the epidemiological surveillance systems linked to the municipal, state, and federal governments. We have no permission to make them available, however these database can be requested at the Brazilian Ministry of Health/Department of Surveillance Health/Leishmaniasis Technical Group (email: leishmanioses@saude.gov.br phone: 55-61-3213-8157; fax: 55-61-3213-8140.

Funding: This study was supported by the following grants: PNPD/Institutional/2011, Brazilian National Leishmaniasis Control Program, PPSUS/MS/CNPq/ FAPEMIG/SES-MG/ grant CBB-APQ-00356-10, CNPQ/Universal 478528/2012-4, and FAPEMIG/PPM. MC and ABR are grateful for CNPq fellowships, and WCV is grateful for the PNPD/CAPES fellowships. The funders had no role in study design, data collection or analysis, decision to publish, or preparation of the manuscript.

Competing Interests: The authors have declared that no competing interests exist.

* Email: mcarneir@icb.ufmg.br

9 These authors contributed equally to this work.

\section{Introduction}

Visceral leishmaniasis (VL) is a severe chronic systemic disease caused by Leishmania infantum parasites in South America, the Mediterranean region, and southwest and central Asia [1]. The disease is transmitted to human and animal hosts by the bite of phlebotomine sand flies, and dogs are the main urban reservoirs $[2,3]$. VL is clinically characterized by prolonged fever, weakness, anorexia, weight loss, hepatomegaly, splenomegaly, hypergammaglobulinemia, and pancytopenia. Over time, without treatment, the disease may progress to severe cachexia, multisystem disease, bleeding, secondary infections, and death $[4,5]$. Bacterial 


\section{Author Summary}

Visceral leishmaniasis $(\mathrm{VL})$ is a fatal disease if not diagnosed and treated appropriately. In the present study, we investigated the risk factors associated with death caused by VL identifiable at the time of clinical suspicion. This study was conducted using all VL cases registered in Brazil during 2007 to 2011. The prognostic factors associated with death caused by VL were bleeding, age (1 year or younger and older than 19 years), Leishmaniahuman immunodeficiency virus (HIV) co-infection, bacterial infection, splenomegaly, edema, weakness, and jaundice. A prognostic scoring system for death caused by VL ranging from 0 to 14 was developed and validated using these risk factors. Patients with scores of 4 or more presented with a worsening prognosis. The scoring system showed good performance in identifying the severe cases. Classification of patients according to their prognosis for death can contribute to improving the clinical management of severe cases and reducing case-fatality rates associated with VL.

infections and bleeding have been the two most prominent symptoms associated with death caused by VL [6].

In Brazil, the occurrence of VL was initially limited to rural areas and small urban locations, but in past decades it has expanded into large urban centers and has become an increasing public health problem throughout the country $[7,8]$. Autochthonous cases were recorded in 26 of the 27 states of Brazil, indicating the dispersion of the disease throughout the country. From 2001 to 2011, 39,780 confirmed VL cases had been reported in Brazil, with an annual average of 3,616 new cases, incidence rate of 2.0 cases per 100,000 inhabitants, and case-fatality rate of $6.5 \%$ during this period $[9,10]$.

Although more specific guidelines for the management of patients with severe VL have been developed in Brazil, the casefatality rate remains high $[9,11,12]$. To reduce mortality, the Brazilian Ministry of Health has instituted specific recommendations through the Visceral Leishmaniasis Control and Surveillance Program (VLCSP). These guidelines include early diagnosis and treatment of human cases, vector control, serological screening and subsequent culling of infected dogs, and health education [11]. According to the VLCSP, all suspected and confirmed cases of VL must be reported to the sanitary authorities and registered in the Reportable Disease Information System (SINAN). This system provides a center for the collection and processing of data and helps to disseminate information generated by the epidemiological surveillance systems linked to the municipal, state, and federal governments. Moreover, this information system contributes to the knowledge of the worldwide morbimortality caused by VL because it helps consolidate the data from institutions such as the Pan American Health Organization and World Health Organization, as recently reported by Alvar et al. [13].

Because reduction of the case-fatality rate is one of the goals of the disease control program, it is important to study the factors associated with death caused by VL. Furthermore, considering that most deaths attributable to VL occur in poor countries [8], the development of a prognostic score using clinical parameters and the dispensing of laboratory results are extremely important. This scoring system can help reduce fatality rates.

Some studies have been performed to propose a prognostic scoring system for death in Brazil, but they used different sources of data to analyze specific age groups or regions of the country [14-16]. The aim of the present study was to identify risk factors associated with death and propose a prognostic scoring system for death by using an historical cohort study including all human VL cases registered in the Brazilian Reportable Disease Information System during 2007 to 2011. The scoring system for death was proposed to assist in early identification of patients at higher risk for death from VL and to guide more focused strategies to improve the clinical management of cases and reduce the case-fatality rate.

\section{Methods}

\section{Ethical statement}

Data analyzed in the present study were provided by the Department of Health Surveillance of Brazilian Ministry of Health (SINAN/CIEVS/DEVEP/MS). The data were anonymous and did not include information that would allow the identification of individuals or that could affect the confidentiality of data. This study included only public secondary data stripped of any individual identifiers. Therefore, ethics committee approval was not required.

\section{Study design and population}

The historical cohort study was conducted in Brazil and included all new cases of VL registered in the SINAN between January 1, 2007 and December 31, 2011. Brazil has an area of 8,515,767.049 $\mathrm{km}^{2}$ and comprises almost half of South America. According to the census by the Brazilian Institute of Geography and Statistics in 2010, the country's population at that time was 190,732,694 inhabitants [10].

The selection criteria for inclusion in the study were as follows: the patient represented a VL case with evolution to cure; the patient represented a VL case with evolution to death; and the primary cause of death of the patient was VL. The exclusion criteria were: no case of VL (ruled out by specific laboratory examinations) or absence of this information (missing); progression to death attributable to other causes; abandonment of treatment; moved to another region during treatment (transference); or absence of this information (missing). As recommended by Snee [17], when collection of new data to validate a model was not possible, simulation of new data was necessary. Splitting the data into two datasets is a reasonable way to accomplish this. The use of one-third of the dataset for validation is necessary because most of the data (two-thirds) must be used to adjust the model to improve the estimation of the parameters [18]. In this sense, the database was randomly subdivided into two series: primary series of patients (two-thirds of eligible cases), which was used to develop the model prognostic score system, and secondary series of patients (one-third of eligible cases), which was used to validate the scoring system. To ensure that the proportion of cures and deaths remained the same in both series, patients were initially divided into two datasets (cures and deaths) ordered by date of notification. In each dataset, a column with the patient's position was generated. For the dataset of cures, 11,563 random numbers between 1 and 17,345, corresponding to two-thirds of the total, were generated. The patients corresponding to the numbers generated were selected for the primary series and the remaining patients were included in the secondary series. The same procedure was used to select patients in the database of deaths, with the generation of 770 random numbers between 1 and 1,156 .

\section{Variables studied}

The epidemiological surveillance system of Brazil has recorded the suspected cases of VL in SINAN using a form comprising the following information: date of notification; health unit responsible for care and notification; address; age; sex; level of schooling; 
occupation of patient; date of the start of symptoms; clinical manifestations (signs and symptoms); co-infections; results of specific laboratory examinations (diagnostic tests); date of beginning of treatment; initial drug used for treatment; drug used after failure of the initial therapy; and evolution of the case. The variables analyzed in the present study were sex and age of patient, date of notification, date of the start of symptoms, clinical manifestations, co-infections (human immunodeficiency virus [HIV]), and evolution of the case (cure or death caused by VL).

\section{Statistical analysis}

Statistical analyses of the data were performed using STATA version 11.0 software (Stata Corp., College Station, TX, USA). To build the scoring system, two-thirds of patients eligible for the study were selected randomly. Univariate logistic regression analysis was used to evaluate the clinical variables according to the occurrence of death from VL. Variables associated with death from VL with a significance level of $p<0.25$ were included in multivariate logistic regression analyses. Variables with more than two categories, such as age, race, and education, were transformed into dummy variables.

Variables presenting statistical significance but with either collinearity or low frequency were excluded from the multivariate analysis. A step-by-step backward selection procedure was used to select the variables and to produce the final multivariate logistic regression models. Only adjusted variables showing a significant association $(p<0.05)$ with the occurrence of death from VL remained in the final model. The likelihood ratio tests were used to adjust these models. The strength of association was determined by odds ratio $(\mathrm{OR})$ with a $95 \%$ confidence interval $(\mathrm{CI})$. The predictive factors of death from VL were used to create a prognosis score. According to the methodology described by Barquet et al. [19], to define the score of each predictive factor, the coefficients of the logistic regression were standardized. Each regression coefficient was divided by the smallest one, and the quotient was rounded to the nearest integer to facilitate clinical use of the system. To estimate the probability of death for the individual $i\left(\mathrm{p}_{\mathrm{i}}\right)$, the following expression was used:

$$
p=\frac{1}{1+e^{-\left(\beta_{0}+\beta_{1} X 1_{i}+\beta_{2} X 2_{i}+\ldots+\beta_{p} X_{p i}\right)}}
$$

where $\beta_{0}, \beta_{1}, \ldots, \beta_{\mathrm{p}}$ are the original estimates for the coefficients of the logistic regression and $X 1_{\mathrm{i}}, X 2_{\mathrm{i}}, \ldots, X \mathrm{p}_{\mathrm{i}}$ are the values for the explicative variables of the individual $i$.

The scoring system for prognosis of death was validated using a validation dataset that included one-third of the eligible patients. The actual evolution of each case, defined as death or cure from VL, was compared with the predictive score. The predictive performance of the scoring system was determined by sensitivity, specificity, accuracy, positive predictive values, negative predictive values and the area under the receiver operating characteristic curve (ROG) [20].

To evaluate the possible existence of differences between cases included (18,501) and cases not included (3,576 cases without final classification) in the study, these two groups were compared according to the variables available in SINAN by using the chisquare test.

\section{Results}

A total of 41,934 suspected VL cases were registered in SINAN from 2007 to 2011; of these, 23,947 were confirmed. Among the patients with confirmed cases, 17,345 cases were cured $(72.5 \%)$ and $1,156(4.8 \%)$ patients died from VL, resulting in 18,501 individuals eligible for analysis. Among the ineligibles cases were $384(1.6 \%)$ patients who died because of other causes, $138(0.6 \%)$ patients who abandoned treatment, $1,348(5.6 \%)$ patients who were moved to another region during the treatment (transference), and 3,576 (14.9\%) patients without data regarding the evolution of the case (missing data). Furthermore, among the suspected cases, $14,608(34.8 \%)$ were not included because infection by $L$. infantum was not confirmed and 3,379 (8.0\%) had missing information regarding final classification (discarded or confirmed as VL) (Fig. 1).

The chi-square test signaled possible differences $(\mathrm{p}<0.05)$ between cases included in and excluded from the study regarding the variables of race, area (urban or rural), and presence of fever and other infections. However, we observed that the categories of the variables have similar proportions (maximum difference of $3 \%)$.

\section{Characteristics of the patients}

The characteristics of patients with VL evaluated in the primary series and in the secondary series are shown in Table 1 . It is noteworthy that all these characteristics were recorded at the time of clinical suspicion of VL. Significant differences between patients in both series were not observed. Among the patients included in the study, there was a predominance of the following characteristics: male sex; age 6 months to 5 years; time to clinical diagnosis $\leq 15$ days; mulatto race; elementary schooling; and residence in an urban area. The main clinical manifestations were fever, weakness, splenomegaly, weight loss, and pallor. Approximately 7\% of patients had Leishmania-HIV co-infection (Table 1).

Modeling the prognostic scoring system (primary series)

The variables obtained by the univariate logistic regression analysis of VL patients were used for modeling the system score (primary series) according to outcome (cure or death) and are shown in Table 2.

Table 3 shows the following predictors of death from VL identified by the multivariate logistic regression analysis: splenomegaly (OR 1.5; 95\% CI 1.2-2.0); edema (OR 1.8; 95\% CI 1.4 2.2); weakness (OR 1.7; 95\% CI 1.2-2.3); bleeding (OR 3.8; $95 \%$ CI 3.0-4.8); jaundice (OR 1.6; 95\% CI 1.3-2.0); Leishmania-HIV co-infection (OR 1.6; 95\% CI 1.2-2.2); bacterial infection (OR 1.9 ; $95 \%$ CI $1.5-2.3)$; and age $(\leq 0.5$ years [OR 8.6 ; $95 \%$ CI $5.3-$ 13.8 ]; $>0.5$ to $\leq 1$ year [OR $2.8 ; 95 \%$ CI $1.8-4.3$ ]; $>19$ to $\leq 50$ years [OR 2.4 95\% CI 1.8-3.1]; $>50$ to $<65$ years [OR 4.0; $95 \%$ CI 2.9-5.7]; and $\geq 65$ years [OR 9.6; 95\% CI 6.7-13.6]).

On the basis of the logistic regression coefficients, one point was assigned for splenomegaly, edema, weakness, jaundice, Leishman$i a$-HIV co-infection, and bacterial infection. Three points were assigned for bleeding. In addition, two points were assigned for children older than 6 months and up to 1 year of age and for adults between 19 and 50 years of age; three points were assigned for age range older than 50 years to younger than 65 years. Five points were assigned for children younger than 6 months and also for adults 65 years of age or older (Table 3). The prediction score ranged from 0 to 14; however, no evaluated patient obtained a score more than 13

\section{Probability of death}

The range of probability of death according to the prognostic score of the patients included in the primary series is presented in Fig. 2. Because the same score can be obtained with different prognostic factors (coefficients of the regression), a range of probability of death was defined. These ranges were calculated 


\section{Total suspected cases of visceral}

\section{leishmaniasis in Brazil, 2007-2011*}
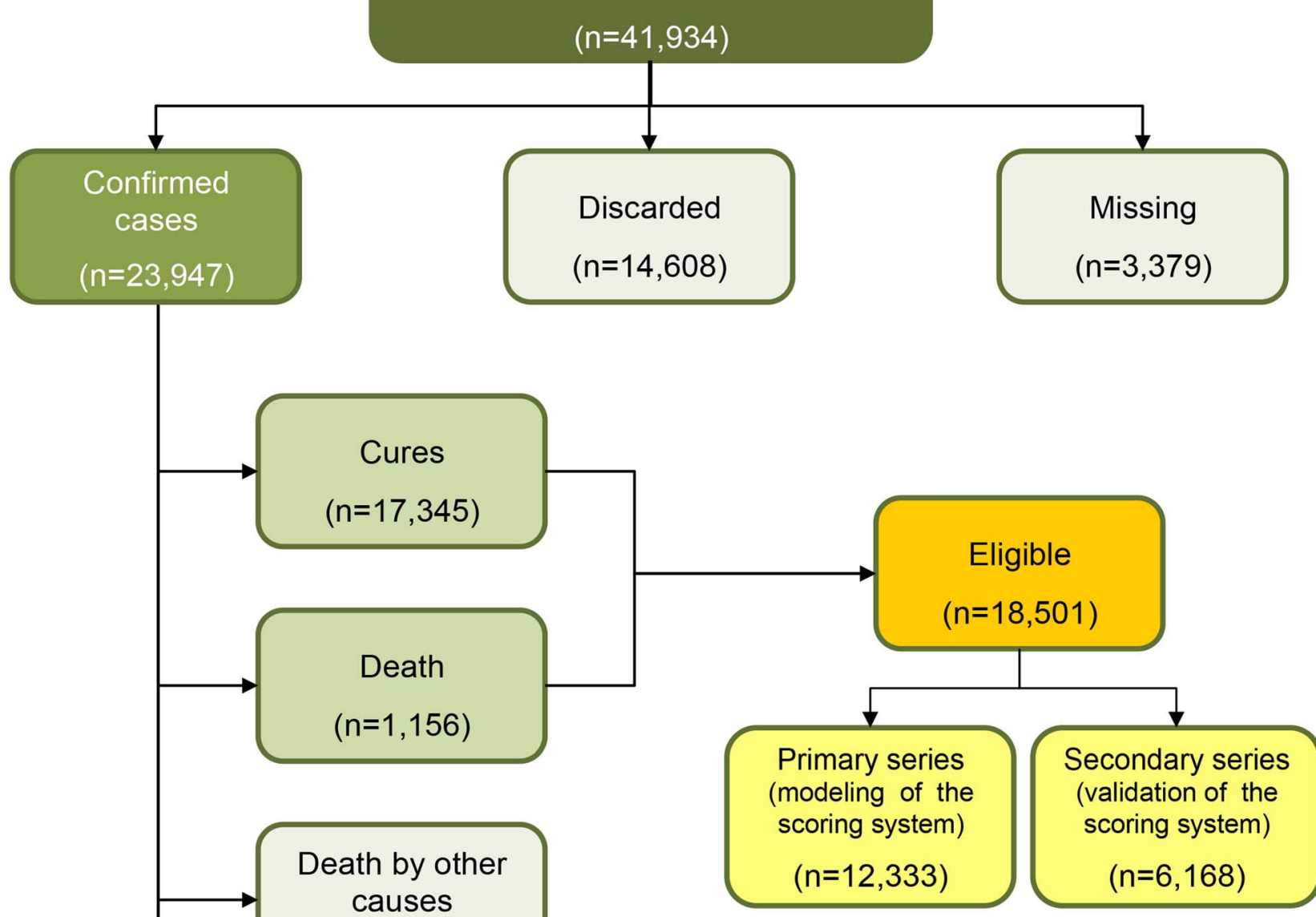

$(n=384)$

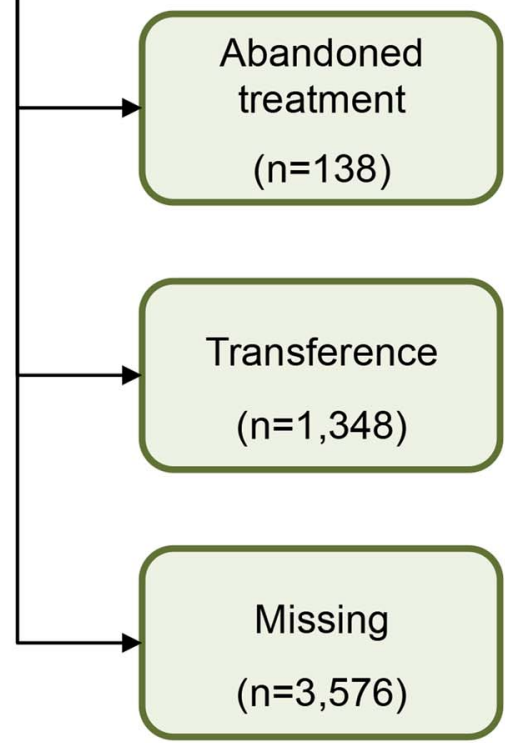

Figure 1. Flow diagram of the population evaluated. ${ }^{*}$ Cases reported in Brazilian Reportable Disease Information System. doi:10.1371/journal.pntd.0003374.g001 
Table 1. Demographics and clinical characteristics of patients with visceral leishmaniasis according to primary and secondary series, Brazil 2007-2011.

\begin{tabular}{|c|c|c|c|}
\hline \multirow[t]{2}{*}{ Variable } & \multirow{2}{*}{$\begin{array}{l}\text { Primary Series* } n=12,333 \\
n(\%)\end{array}$} & \multirow{2}{*}{$\begin{array}{l}\text { Secondary Series } \# \text { n= 6,168 } \\
\mathrm{n}(\%)\end{array}$} & \multirow[t]{2}{*}{$P$} \\
\hline & & & \\
\hline Male & $7,613(61.7)$ & $3,746(60.7)$ & 0.19 \\
\hline \multicolumn{4}{|l|}{ Age (years) } \\
\hline$\leq 0.5$ & $252(2.0)$ & $138(2.2)$ & \\
\hline$>0.5$ to $\leq 1$ & $682(5.5)$ & $301(4.9)$ & \\
\hline$>1$ to $\leq 5$ & $3,410(27.7)$ & $1,758(28.5)$ & \\
\hline$>5$ to $\leq 19$ & $2,564(20.8)$ & $1,239(20.1)$ & \\
\hline$>19$ to $\leq 50$ & $3,774(30.6)$ & $1,945(31.5)$ & \\
\hline$>50$ to $<65$ & $1,044(8.5)$ & $515(8.4)$ & \\
\hline$\geq 65$ & $607(4.9)$ & $272(4.4)$ & 0.14 \\
\hline \multicolumn{4}{|c|}{ Time to clinical diagnosis (days)** } \\
\hline$\leq 15$ & $5,101(41.4)$ & $2,482(40.2)$ & \\
\hline$>15$ to $\leq 30$ & $2,553(20.7)$ & $1,282(20.8)$ & \\
\hline$>30$ to $\leq 60$ & $2,219(18.0)$ & $1,157(18.8)$ & \\
\hline$>60$ & $2,460(19.9)$ & $1,247(20.2)$ & 0.43 \\
\hline \multicolumn{4}{|l|}{ Race } \\
\hline White & $2,311(20.8)$ & $1,116(20.1)$ & \\
\hline Black & $912(8.2)$ & $505(9.1)$ & \\
\hline Asian & $106(1.0)$ & $56(1.0)$ & \\
\hline Mulatto & $7,652(69.1)$ & $3,817(68.9)$ & \\
\hline Indigenous & $97(0.9)$ & $50(0.9)$ & 0.34 \\
\hline \multicolumn{4}{|l|}{ Education } \\
\hline College & $130(1.4)$ & $61(1.3)$ & \\
\hline High school & $803(8.3)$ & $407(8.4)$ & \\
\hline Elementary school & $2,058(21.4)$ & $1,019(21.1)$ & \\
\hline Illiterate & $1,591(16.5)$ & $770(16.0)$ & \\
\hline Not applicable $(<5$ years $)$ & $5,048(52.4)$ & $2,569(53.2)$ & 0.85 \\
\hline \multicolumn{4}{|l|}{ Area } \\
\hline Urban & $9,302(77.7)$ & 4,667 (77.9) & \\
\hline Rural & $2,664(22.3)$ & $1,325(22.1)$ & 0.82 \\
\hline \multicolumn{4}{|l|}{ Clinical manifestation } \\
\hline Fever & $11,040(92.3)$ & $5,547(92.4)$ & 0.82 \\
\hline Weakness & $9,398(79.8)$ & $4,757(80.6)$ & 0.22 \\
\hline Edema & $2,703(23.9)$ & $1,353(23.9)$ & 0.96 \\
\hline Weight loss & $8,489(72.3)$ & $4,270(72.5)$ & 0.82 \\
\hline Cough and/or diarrhea & $5,440(46.7)$ & $2,763(47.4)$ & 0.37 \\
\hline Pallor & $8,085(70.5)$ & $4,096(71.3)$ & 0.30 \\
\hline Splenomegaly & $8,754(75.1)$ & 4,391 (75.4) & 0.63 \\
\hline Bacterial infection & $2,600(23.6)$ & $1,287(23.5)$ & 0.78 \\
\hline Bleeding & $1,026(9.2)$ & $516(9.2)$ & 0.93 \\
\hline Hepatomegaly & $7,663(66.3)$ & $3,846(66.6)$ & 0.71 \\
\hline Jaundice & $2,500(22.2)$ & $1,295(23.0)$ & 0.27 \\
\hline Other manifestations & $2,245(21.0)$ & $1,221(20.8)$ & 0.77 \\
\hline Leishmania-HIV co-infection & $610(7.0)$ & $295(6.8)$ & 0.58 \\
\hline
\end{tabular}


Table 2. Univariate analysis of the prognostic factors for death in visceral leishmaniasis, Brazil 2007-2011.

\begin{tabular}{|c|c|c|c|c|c|}
\hline \multirow[t]{2}{*}{ Variable } & \multirow[t]{2}{*}{ Category } & \multirow{2}{*}{$\begin{array}{l}\text { Deaths } \mathrm{n}=\mathbf{7 7 0} \\
\mathrm{n}(\%)\end{array}$} & \multirow{2}{*}{$\begin{array}{l}\text { Cures } n=11,563 \\
n(\%)\end{array}$} & \multirow[t]{2}{*}{ OR $(95 \% \mathrm{Cl})$} & \multirow[t]{2}{*}{$p$} \\
\hline & & & & & \\
\hline \multirow[t]{2}{*}{ Sex } & Female & $263(34.2)$ & 4,457 (38.5) & & \\
\hline & Male & $507(65.8)$ & $7,106(61.5)$ & $1.2(1.0-1.4)$ & 0.01 \\
\hline \multirow[t]{6}{*}{ Age (years) } & $>1$ to $\leq 19$ & $167(21.7)$ & $5,807(50.2)$ & & \\
\hline & $\leq 0.5$ & $35(4.6)$ & $217(1.9)$ & $5.6(3.8-8.3)$ & 0.00 \\
\hline & $>0.5$ to $\leq 1$ & $55(7.1)$ & $627(5.4)$ & $3.1(2.2-4.2)$ & 0.00 \\
\hline & $>19$ to $\leq 50$ & $265(34.4)$ & 3,509 (30.4) & $2.6(2.2-3.2)$ & 0.00 \\
\hline & $>50$ to $<65$ & $121(15.7)$ & $924(8.0)$ & $4.6(3.6-5.8)$ & 0.00 \\
\hline & $\geq 65$ & $127(16.5)$ & $480(4.1)$ & $9.2(7.2-11.8)$ & 0.00 \\
\hline \multirow[t]{4}{*}{ Time to clinical diagnosis (days)* } & $\leq 15$ & $254(33.0)$ & $4,847(41.9)$ & & \\
\hline & $>15$ to $\leq 30$ & $152(19.7)$ & $2,401(20.8)$ & $1.2(0.9-1.5)$ & 0.07 \\
\hline & $>30$ to $\leq 60$ & $138(17.9)$ & 2,081 (18.0) & $1.3(1.0-1.6)$ & 0.03 \\
\hline & $>60$ & $226(29.4)$ & $2,234(19.3)$ & $1.9(1.6-2.3)$ & 0.00 \\
\hline \multirow[t]{2}{*}{ Fever } & No & $44(6.0)$ & $872(7.8)$ & & \\
\hline & Yes & $684(94.0)$ & $10,356(92.2)$ & $1.3(0.9-1.8)$ & 0.09 \\
\hline \multirow[t]{2}{*}{ Weakness } & No & $73(10.2)$ & 2,305 (20.8) & & \\
\hline & Yes & $642(89.8)$ & $8,756(79.2)$ & $2.3(1.8-3.0)$ & 0.00 \\
\hline \multirow[t]{2}{*}{ Edema } & No & $377(55.0)$ & $8,225(77.5)$ & & \\
\hline & Yes & $308(45.0)$ & 2,395 (22.5) & $2.8(2.4-3.3)$ & 0.00 \\
\hline \multirow[t]{2}{*}{ Weight loss } & No & $140(20.0)$ & $3,109(28.2)$ & & \\
\hline & Yes & $560(80.0)$ & $7,929(71.8)$ & $1.6(1.3-1.9)$ & 0.00 \\
\hline \multirow[t]{2}{*}{ Cough and/or diarrhea } & No & $327(46.4)$ & $5,891(53.8)$ & & \\
\hline & Yes & $378(53.6)$ & $5,062(46.2)$ & $1.3(1.2-1.6)$ & 0.00 \\
\hline \multirow[t]{2}{*}{ Pallor } & No & $140(20.4)$ & $3,237(30.0)$ & & \\
\hline & Yes & 548 (79.6) & $7,537(70.0)$ & $1.7(1.4-2.0)$ & 0.00 \\
\hline \multirow[t]{2}{*}{ Splenomegaly } & No & $112(15.8)$ & 2,792 (25.5) & & \\
\hline & Yes & $598(84.2)$ & $8,156(74.5)$ & $1.8(1.5-2.2)$ & 0.00 \\
\hline \multirow[t]{2}{*}{ Bacterial infection } & No & $355(53.5)$ & $8,044(77.8)$ & & \\
\hline & Yes & 309 (46.5) & 2,291 (22.2) & $3.0(2.6-3.6)$ & 0.00 \\
\hline \multirow[t]{2}{*}{ Bleeding } & No & $448(66.8)$ & $9,745(92.4)$ & & \\
\hline & Yes & $223(33.2)$ & $803(7.6)$ & $6.0(5.0-7.2)$ & 0.00 \\
\hline \multirow[t]{2}{*}{ Hepatomegaly } & No & $155(21.7)$ & $3,743(34.5)$ & & \\
\hline & Yes & $561(78.3)$ & $7,102(65.5)$ & $1.9(1.6-2.3)$ & 0.00 \\
\hline \multirow[t]{2}{*}{ Jaundice } & No & $411(60.8)$ & 8,331 (78.9) & & \\
\hline & Yes & $265(39.2)$ & 2,235 & $2.4(2.0-2.8)$ & 0.00 \\
\hline \multirow[t]{2}{*}{ Leishmania-HIV co-infection } & No & $463(86.9)$ & 7,586 (93.3) & & \\
\hline & Yes & 70 (13.1) & $540(6.7)$ & $2.1(1.6-2.8)$ & 0.00 \\
\hline
\end{tabular}

*Time between the dates of onset of symptoms and notification (days); $\mathrm{Cl}$, confidence interval; HIV, human immunodeficiency virus; OR, odds ratio. doi:10.1371/journal.pntd.0003374.t002

based on the sum of the smallest and largest regression coefficients for each point comprising the score. For example, for a score of 4, the range of probability of death was calculated as follows:

$$
\begin{aligned}
& p_{\text {minor }}=\frac{1}{1+e^{-(-5.12+1.34+0.43)}}=0.034 \text { and } \\
& p_{\text {major }}=\frac{1}{1+e^{-(-5.12+0.63+0.57+1.02)}}=0.052
\end{aligned}
$$

The idea behind the presentation of a range of probability is that a patient can have a given value for the score in different ways. For example, a patient older than 1 year or younger than 20 years can have a score of 4 if that patient presents with splenomegaly and bleeding $\left(\mathrm{p}_{\text {minor }}\right)$, or if the patient is older than 0.5 years or younger than 1 year and presents with bacterial infection and edema, ( $\left.p_{\text {major }}\right)$. The standardization of the coefficients gives the score of 4 for both situations. However, the probability of death is calculated based on the original coefficients, which leads to some difference in values. A score of 3 or less corresponds to a probability of death of 
Table 3. Predictive scoring system for death attributable to visceral leishmaniasis, Brazil 2007-2011.

\begin{tabular}{|c|c|c|c|c|}
\hline Variable & Adjusted OR (95\% Cl) & Regression Coefficient & Standard Error & Points \\
\hline Splenomegaly & $1.5(1.2-2.0)$ & 0.43 & 0.14 & 1 \\
\hline Edema & $1.8(1.4-2.2)$ & 0.57 & 0.11 & 1 \\
\hline Weakness & $1.7(1.2-2.3)$ & 0.50 & 0.17 & 1 \\
\hline Bleeding & $3.8(3.0-4.8)$ & 1.34 & 0.12 & 3 \\
\hline Jaundice & $1.6(1.3-2.0)$ & 0.48 & 0.11 & 1 \\
\hline \multicolumn{5}{|l|}{ Age (years) } \\
\hline$\leq 0.5$ & $8.6(5.3-13.8)$ & 2.14 & 0.24 & 5 \\
\hline$>0.5$ to $\leq 1$ & $2.8(1.8-4.3)$ & 1.02 & 0.23 & 2 \\
\hline$>1$ to $\leq 19$ & 1.0 & - & - & 0 \\
\hline$>19$ to $\leq 50$ & $2.4(1.8-3.1)$ & 0.87 & 0.14 & 2 \\
\hline$>50$ to $<65$ & $4.0(2.9-5.7)$ & 1.34 & 0.17 & 3 \\
\hline$\geq 65$ & $9.6(6.7-13.6)$ & 2.25 & 0.18 & 5 \\
\hline Leishmania-HIV co-infection & $1.6(1.2-2.2)$ & 0.50 & 0.16 & 1 \\
\hline Bacterial infection & $1.9(1.5-2.3)$ & 0.63 & 0.11 & 1 \\
\hline
\end{tabular}

Constant of the model $=-5.12$ and standard error $=0.20$.

\#Each coefficient was divided by 0.43 and the quotient was rounded to the nearest integer to determine the number of points assigned to that predictor of death from visceral leishmaniasis.

$\mathrm{Cl}$, confidence interval; HIV, human immunodeficiency virus; OR, odds ratio.

doi:10.1371/journal.pntd.0003374.t003

less than $3.2 \%$. It is noteworthy that a patient with a score of 4 has approximately $4.5 \%$ probability of death from VL, which is relevant from a clinical point of view. The ranges of probability of death are $4.8 \%$ to $8.3 \%$ and $7.2 \%$ to $13.0 \%$ when the score is 5 and when the score is 6 , respectively. When the patient has a score of 11 , the range of probability of death increases to $44.3 \%$ to $56.0 \%$; with a score of 14 , the range of probability of death is $81.3 \%$ to $82.9 \%$ (Fig. 2).

\section{Validation of the prognostic scoring system (secondary series)}

The reliability and discriminatory power of the models were good. The lowest scores showed high sensitivity and low specificity, and the opposite was observed for higher scores. The lethality observed in the validation group (secondary series) was similar to probability of death estimated by the score and did not vary by many percentage points, with the exception of scores 11, 12, and 13. Miscalibrations for patients with predicted low risk and high risk during the internal validation were observed. These miscalibrations might be related to the imprecision attributable to the low number of patients in the lowest risk group and in the highest risk group. It was also observed that a score of 4 showed a slightly higher than expected probability of mortality. The sensitivity, specificity, and accuracy of a score of 4 were 89.4, 51.2, and 53.5 for primary series and 86.6, 51.2 and 53.2 for secondary series respectively (Table 4).

The areas under the ROC curves were 0.80 (95\% CI 0.78-0.82) for the derivation set and 0.78 (95\% CI 0.75-0.81) for the validation set (Fig. 3A). No statistically significant differences were found when comparing derivation and validation curves $(\mathrm{p}>0.05)$.

Hence, the prognostic score of 4 was chosen to evaluate the positive and negative predictive values versus several values of probability of death. It was observed that the positive predictive values ranged from $8.8 \%$ to $37.9 \%$ when the case-fatality rate ranged from $5 \%$ to $25 \%$. Negative predictive values ranged from $98.9 \%$ to $93.6 \%$ (Fig. $3 \mathrm{~B}$ ).

\section{Discussion}

This is the first nationwide study of prognostic factors of death from VL in Brazil. The findings of this investigation contribute greatly to the identification and management of severe VL cases, because a prognostic scoring system for death from VL has been developed and validated. At the time of clinical suspicion of VL, death was reliably predicted by the presence of splenomegaly, edema, weakness, bleeding, jaundice, age (1 year or younger and older than 19 years old), Leishmania-HIV co-infection, and presence of bacterial infection. The majority of these risk factors for death can be easily observed by a physician or another health professional in basic health units, allowing early detection of VL cases potentially severe enough for redirection to specialized health services. It is known that correct management of cases by local health services plays an important role in preventing death caused by this disease. According to the clinical point of view and the predictive scoring system proposed here, a patient with a score of 4 or more should have maximum surveillance and attention, because this score presents a risk of death of approximately $4.5 \%$ or more. Avoidance of death should be the aim of health care. Hospitalization should be required for all these groups because specific treatment and measures such as hydration, antipyretics, antibiotics, blood therapy, and nutritional support, should be administered and testing to monitor treatment should be performed [12]. According to the clinical point of view and the predictive scoring system proposed here, a patient with a score of 0 or 1 has a low risk of death $(<1.1 \%)$, indicating that outpatient treatment is potentially safe. Patients with a score of 2 or 3 have a 


\section{Score}

\section{Range of the probability of death (\%)}

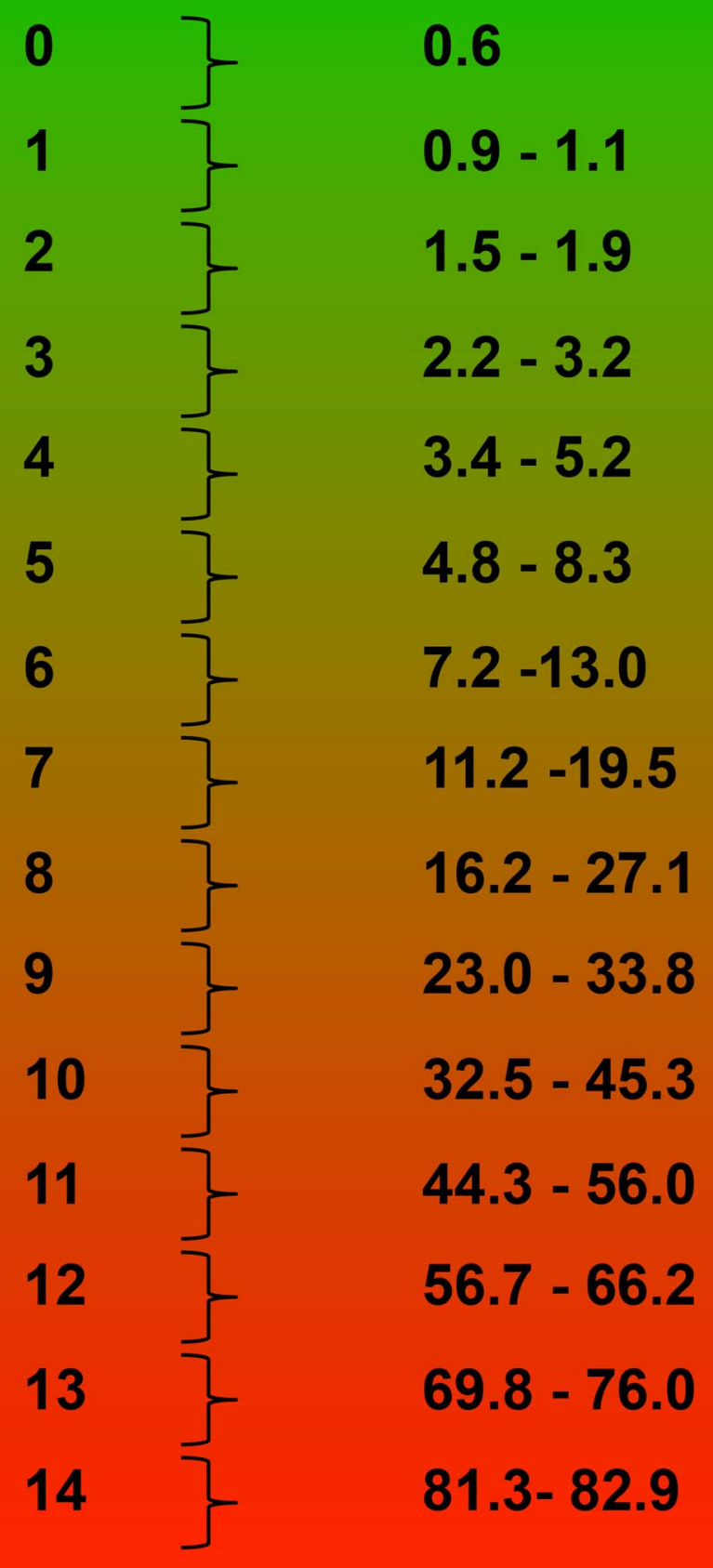

Figure 2. Prognostic scoring system and range of probability of death from visceral leishmaniasis. doi:10.1371/journal.pntd.0003374.g002

risk of less than $3.2 \%$, which may indicate treatment during a short stay in the hospital or very close follow-up on an outpatient basis. A score of 4 showed high negative predictive value, confirming that patients with a score less than 4 have little chance of death from VL. The positive predictive value was low because of the low cutoff score.
Guidelines indicating clinical recommendations for lethality reduction of VL, including a scoring system used by the leishmaniasis national control program, was published recently. This scoring system was developed using patients from northeast Brazil and clinical and laboratory data; bleeding, edema, jaundice, bacterial infection, and AIDS were also observed to be risk factors 


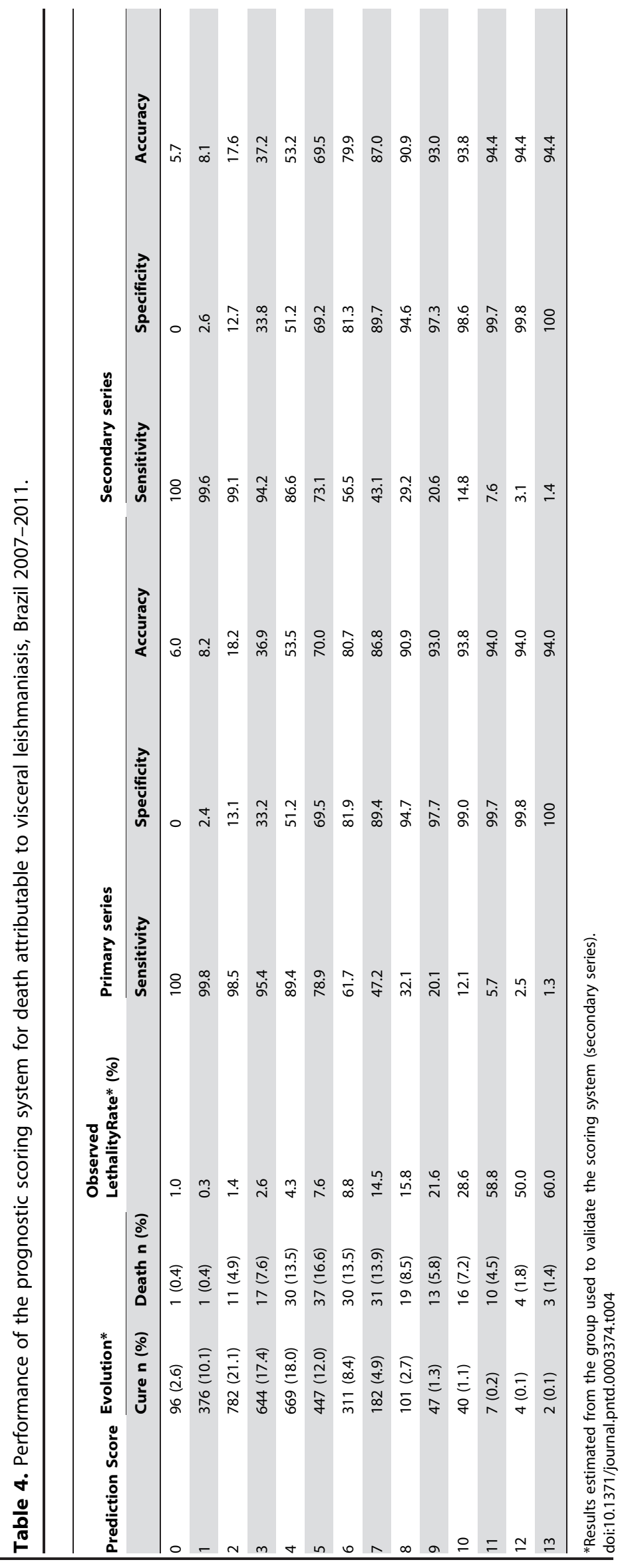


A

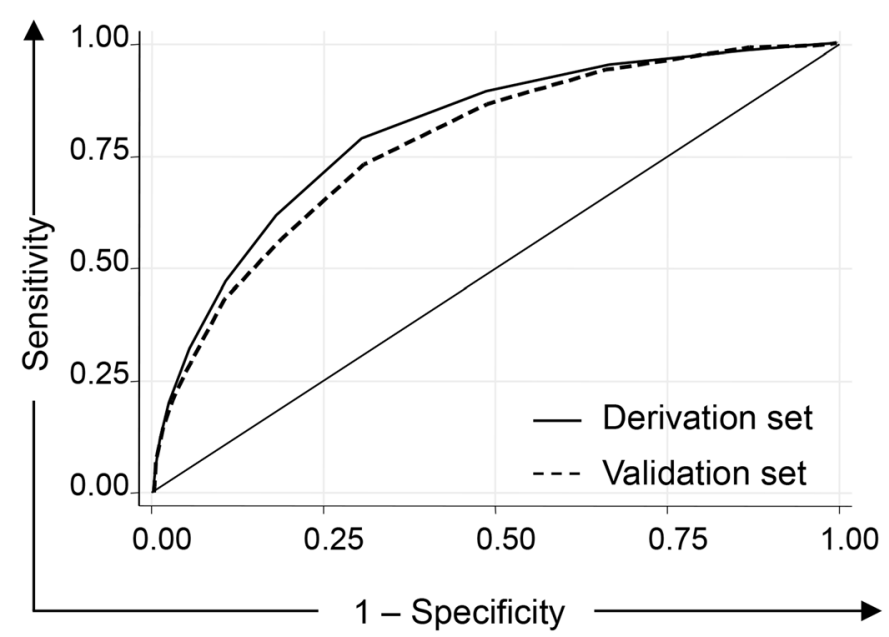

B

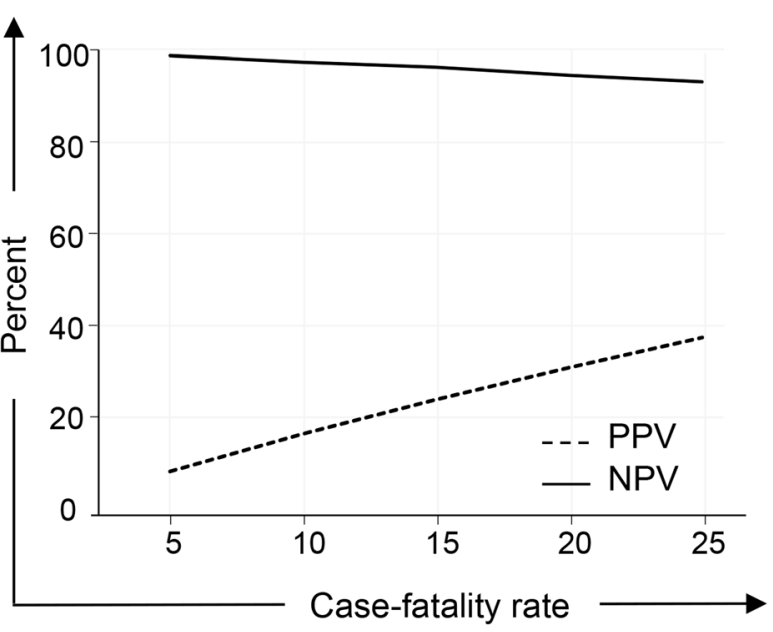

Figure 3. Receiver operating curves (derivation and validation sets) and predictive values of prognostic scoring system. PPV, positive predictive value; NPV, negative predictive value. doi:10.1371/journal.pntd.0003374.g003

associated with death [12]. The two scoring systems differ mainly regarding laboratory data, which are not available in SINAN. Although most predictors identified in this study have been previously recognized as factors of prognostic importance in VL $[6,14,15,21,22]$, herein we show the magnitude and influence of these factors on prognosis of the death. It is important to emphasize that the proposed score was validated with a different dataset than the one used to estimate the model. Recently, a metaanalysis regarding risk factors for adverse prognosis and death from VL observed that the main limitation of the studies was the absence of validation procedures for the few prognostic models developed so far [22].

Among the factors identified, two (age and bleeding) were the major predictors of death from VL. Patients up to 6 months old and those 65 years or older have a worse prognosis (score 5), followed by those aged older than 50 years to younger than 65 years (score 3). Patients older than 6 months and up to 1 year and those older than 19 years to age 50 years presented lower scores (score 2). According to Brazilian Guidelines for Managing Severe Disease, every VL patient younger than age 6 months or older than 65 years should be considered as having a severe case. Children between the ages of 6 months and 1 year and adults between the ages of 50 years and 65 years should also receive greater attention, because they are more likely to experience progression to severe disease [23]. However, the prospective study by Caldas et al. [24] did not identify differences in clinical and laboratory parameters between children and adults that would indicate different clinical management. Children are generally more susceptible to infectious diseases with relatively higher frequencies of neutropenia and lymphocytosis, because neutrophils are the first-line of defense against bacterial infections [24,25]. A case-control study conducted in Teresina (northeastern Brazil) revealed that very young children were at higher risk for bacterial infections, diarrhea, and severe anemia, thus contributing to their worse prognosis [6]. Additionally, other authors also observed a poor prognosis in younger children and in the elderly $[14,21,26,27]$.

Some studies show that the presence of bleeding and bacterial infections account for the most fatal complications [6,14,16,21,28,29]. Bleeding is part of the coagulopathy associated with the systemic inflammatory response; in VL, thrombocytopenia and hepatic dysfunction contribute to hemorrhagic complications [6]. In severe cases, hemorrhagic phenomena are probably associated with disseminated intravascular coagulation [5], such as the activation of coagulation and fibrinolysis initiated as part of the inflammatory response by a mechanism similar to that established for sepsis [30]. In addition, patients with VL are characteristically neutropenic, and this immunosuppression increases the risk for secondary bacterial infections and other concealed infections, contributing to a higher risk of death [29].

Our data showed that Leishmania-HIV co-infection is a factor that worsens the prognosis of VL. In fact, the clinical course and prognosis for these individuals differ from those of non-HIVinfected patients [31]. Leishmania-HIV co-infection is characterized by significantly higher drug toxicity, relapse rates, and mortality rates and lower cure rates than for non-HIV-infected individuals with VL [6,31,32]. Co-infection exerts a synergistic detrimental effect on the cellular immune response because it targets similar immune cells [33]. The Brazilian Ministry of Health recommends HIV testing for all VL patients and treatment with liposomal amphotericin B for all those who are co-infected [12]. This assures major reliability of this variable in the prognostic scoring system for death.

Several studies have reported that splenomegaly, edema, weakness, and jaundice are associated with worse prognosis $[23,34]$. Our score system suggests that these clinical manifestations could predict VL mortality and contribute to better clinical management.

Although VL is a reportable disease in Brazil, the underreporting of cases and deaths with a non-specific clinical picture of disease cannot be ruled out. However, SINAN covers all public and private health care systems and their various levels of complexity. Furthermore, it is noteworthy that the medication used for treatment is solely dispensed by the government, which has minimized underreporting. Despite the improvement in the Brazilian notification systems in the past two decades, several data were missing regarding the final classification of cases (confirmed or discarded) and outcome (cure, death from VL, death by other causes, abandonment of treatment, or transference). These missing data represent a limitation in this study. Although some variables have shown significant differences between the individuals 
included and excluded from the study, these differences between each category were minimal (up to $3 \%$ ) and possibly did not compromise our results. These differences occurred because the number of individuals studied was much larger (approximately seven-fold) than the number excluded. However, the need to exclude the patients from the study because of lack of proper registration in SINAN points to the need to improve this information system and the quality of surveillance of VL in Brazil. The variable "time to clinical diagnosis", defined as the time between the dates of onset of symptoms and notification, was significant only in univariate analysis, in spite of its importance for prognosis of VL patients. The lack of association is likely attributable to recall bias and the difficulty in accurately defining the onset of symptoms. Another possible limitation is that our analyses did not take into account all possible factors that could contribute to unfavorable evolution of VL, such as nutritional status and the presence of other comorbidities (autoimmune diseases, kidney failure, liver or heart diseases, alcoholism, and other drug abuse) and interventions (treatment and clinical management) because these are not collected in the SINAN information system. The miscalibrations found in the scoring system for patients at lowest risk or highest risk (that is, scores 0-1 or 11-13) are a potential limitation; however, they are unlikely to change clinical decision-making.

Despite these limitations, we believe that our prognostic scoring system has good performance and provides relevant information, such as the probability of death according to the signs and symptoms present at the moment of clinical suspicion, thus helping to improve the clinical management of patients with VL. It was developed using all cases recorded throughout the Brazilian territory over the course of 5 years (large sample size), which ensures excellent validity (internal) of the study. Furthermore, by not relying on laboratory results, this scoring system can be used in any health facility, even in the most basic facilities and in those located in more remote areas of the large Brazilian territory. This also allows the possibility of using (and evaluating) this prognostic system in less developed countries with occurrences of VL. Although this study was based on VL cases in Brazil, where $L$. infantum is a common agent of disease, we believe that our scoring system may be useful also in the Old World, where VL is caused by L. donovani. Studies conducted in endemic areas in the Old World and in the New World have showed some similar risk factors for death among these species of Leishmania [14-16,2628 . However, the scoring system can have poor performance in other populations because of the differences between the

\section{References}

1. Desjeux P (2004) Leishmaniasis: current situation and new perspectives. Comp Immunol Microbiol Infect Dis 27: 305-318.

2. Coura-Vital W, Marques MJ, Veloso VM, Roatt BM, Aguiar-Soares RD, et al. (2011) Prevalence and factors associated with Leishmania infantum infection of dogs from an urban area of Brazil as identified by molecular methods. PLoS Negl Trop Dis 5: e1291.

3. Killick-Kendrick R (1999) The biology and control of phlebotomine sand flies. Clin Dermatol 17: 279-289.

4. Murray HW, Berman JD, Davies CR, Saravia NG (2005) Advances in leishmaniasis. Lancet 366: 1561-1577.

5. Lomtadze ML, Khochava MA, Shalamberidze IA, Kharaishvili VI, Vorob'eva EO (2005) [Study of intravascular coagulation activation markers in patients with visceral leishmaniasis]. Georgian Med News: 47-50.

6. Costa CH, Werneck GL, Costa DL, Holanda TA, Aguiar GB, et al. (2010) Is severe visceral leishmaniasis a systemic inflammatory response syndrome? A case control study. Rev Soc Bras Med Trop 43: 386-392.

7. Harhay MO, Olliaro PL, Costa DL, Costa CH (2011) Urban parasitology: visceral leishmaniasis in Brazil. Trends Parasitol 27: 403-409.

8. World Health Organization (2010) Working to overcome the global impact of neglected tropical diseases:First WHO report on neglected tropical diseases. In: WHO, editor. Geneva. pp. 184 characteristics of patients, health care systems and diagnostic methods [18], and species of etiological agents. Therefore, it is necessary to perform external validation of the scoring system in such areas to determinate its predictive performance.

This scoring system should be used in clinical practice after an external validation method. Thus, it is essential to quantify its predictive performance with a new series of patients, ideally in a different location $[35,36]$. The present scoring system constitutes the first step in the formulation of a consistent prognostic model that can be improved with the inclusion of other data (e.g., of other comorbidities). As with any predictive score, it should not be used in a definitive manner; clinical decisions should remain dependent on clinical judgment.

\section{Conclusion}

At the time of clinical suspicion of $\mathrm{VL}$, the ability to predict death without the need for laboratory results makes our scoring system simple and useful in health facilities of any degree of complexity. The classification of patients according to their prognosis for death can assist decision-making regarding transference to hospital for care and admission to the intensive care unit, and can maximize surveillance, early detection, and treatment of complications. Therefore, our prognostic scoring system for VL may suggest changes in surveillance strategies to improve the clinical management of severe cases and may contribute to reduction of the case-fatality rate.

\section{Supporting Information}

\section{S1 Supporting Information STROBE checklist. (DOCX)}

\section{Acknowledgments}

We thank the staff of the Technical Group of Leishmaniasis (Department of Health Surveillance/Brazilian Ministry of Health) for providing the Brazilian VL database. We would like to thank Dr. Ana Rabello by a critical reading of the manuscript.

\section{Author Contributions}

Conceived and designed the experiments: WCV VEMdA IAR FFA ABR MC. Performed the experiments: WCV VEMdA IAR MC. Analyzed the data: WCV VEMdA IAR FFA ABR MC. Contributed reagents/ materials/analysis tools: MC. Wrote the paper: WCV VEMdA IAR FFA ABR MC.

9. Ministério da saúde (2013) Sistema de Informação de Agravos de NotificaçãoSinan Net. Avaliable at: http://dtr2004.saude.gov.br/sinanweb/tabnet/ tabnet?sinannet/leishvi/bases/leishvbrnet.def. Accessed: 2 December 2013.

10. IBGE (2013) Instituto Brasileiro de Geografia e Estatística. Censo Demográfico 2010. Available: <http://www.ibge.gov.br/>. Accessed: 10 November 2013.

11. Ministério da Saúde (2006) Manual de vigilância e controle da leishmaniose visceral, 1st ed. Secretaria de Vigilância em Saúde, Brasília. Available: http://portal.saude.gov. br/portal/arquivos/pdf/manual_leish_visceral2006.pdf Accessed 8 December.

12. Ministry of Health of Brazil (2011) Visceral leishmaniasis: clinical recommendations for lethality reduction. Secretaria de Vigilância em Saúde. Departamento de Vigilância Epidemiológica, Brasília: 78p.

13. Alvar J, Velez ID, Bern C, Herrero M, Desjeux P, et al. (2012) Leishmaniasis worldwide and global estimates of its incidence. PLoS One 7: e35671.

14. de Araujo VE, Morais MH, Reis IA, Rabello A, Carneiro M (2012) Early clinical manifestations associated with death from visceral leishmaniasis. PLoS Negl Trop Dis 6: e1511.

15. Sampaio MJ, Cavalcanti NV, Alves JG, Filho MJ, Correia JB (2010) Risk factors for death in children with visceral leishmaniasis. PLoS Negl Trop Dis 4: e877.

16. Werneck GL, Batista MS, Gomes JR, Costa DL, Costa CH (2003) Prognostic factors for death from visceral leishmaniasis in Teresina, Brazil. Infection 31: 174-177. 
17. Snee RD (1977) Validation of Regression Models: Methods and Examples. Technometrics 19: 415-428.

18. Altman DG, Vergouwe Y, Royston P, Moons KG (2009) Prognosis and prognostic research: validating a prognostic model. BMJ 338: b605.

19. Barquet N, Domingo P, Cayla JA, Gonzalez J, Rodrigo C, et al. (1997) Prognostic factors in meningococcal disease. Development of a bedside predictive model and scoring system. Barcelona Meningococcal Disease Surveillance Group. JAMA 278: 491-496.

20. Szklo M, Nieto J (2007) Epidemiology: Beyond the Basics.

21. Madalosso G, Fortaleza GM, Ribeiro AF, Cruz LL, Nogueira PA, et al. (2012) American visceral leishmaniasis: factors associated with lethality in the state of sao paulo, Brazil. J Trop Med 2012: 281572.

22. Belo VS, Struchiner CJ, Barbosa DS, Nascimento BW, Horta MA, et al. (2014)

Risk factors for adverse prognosis and death in American visceral leishmaniasis: a meta-analysis. PLoS Negl Trop Dis 8: e2982.

23. Ministério da Saúde (2006) Leishmaniose visceral grave: normas e condutas/ Ministério da Saúde, Secretaria de Vigilância em Saúde, Departamento de Vigilância Epidemiológica. Brasília: Editora do Ministério da Saúde, 2006. Ministério da Saúde.

24. Caldas AJ, Costa J, Aquino D, Silva AA, Barral-Netto M, et al. (2006) Are there differences in clinical and laboratory parameters between children and adults with American visceral leishmaniasis? Acta Trop 97: 252-258.

25. Rocha NA, Oliveira MJ, Franco LF, Junior GB, Alves MP, et al. (2013) Comparative analysis of pediatric and adult visceral leishmaniasis in Brazil. Pediatr Infect Dis J 32: e182-185.

26. Braga AS, Toledo Junior AC, Rabello A (2013) Factors of poor prognosis of visceral leishmaniasis among children under 12 years of age. A retrospective monocentric study in Belo Horizonte, State of Minas Gerais, Brazil, 2001-2005. Rev Soc Bras Med Trop 46: 55-59.
27. Mueller Y, Mbulamberi DB, Odermatt P, Hoffmann A, Loutan L, et al. (2009) Risk factors for in-hospital mortality of visceral leishmaniasis patients in eastern Uganda. Trop Med Int Health 14: 910-917.

28. Collin S, Davidson R, Ritmeijer K, Keus K, Melaku Y, et al. (2004) Conflict and kala-azar: determinants of adverse outcomes of kala-azar among patients in southern Sudan. Clin Infect Dis 38: 612-619.

29. Andrade TM, Carvalho EM, Rocha H (1990) Bacterial infections in patients with visceral leishmaniasis. J Infect Dis 162: 1354-1359.

30. Esmon CT (2004) The impact of the inflammatory response on coagulation. Thromb Res 114: 321-327.

31. Alvar J, Aparicio P, Aseffa A, Den Boer M, Canavate C, et al. (2008) The relationship between leishmaniasis and AIDS: the second 10 years. Clin Microbiol Rev 21: 334-359, table of contents.

32. Pintado V, Martin-Rabadan P, Rivera ML, Moreno S, Bouza E (2001) Visceral leishmaniasis in human immunodeficiency virus (HIV)-infected and non-HIVinfected patients. A comparative study. Medicine (Baltimore) 80: 54-73.

33. Olivier M, Badaro R, Medrano FJ, Moreno J (2003) The pathogenesis of Leishmania/HIV co-infection: cellular and immunological mechanisms. Ann Trop Med Parasitol 97 (Suppl 1): 79-98.

34. Seaman J, Mercer AJ, Sondorp HE, Herwaldt BL (1996) Epidemic visceral leishmaniasis in southern Sudan: treatment of severely debilitated patients under wartime conditions and with limited resources. Ann Intern Med 124: 664-672.

35. Reilly BM, Evans AT (2006) Translating clinical research into clinical practice: impact of using prediction rules to make decisions. Ann Intern Med 144: $201-$ 209.

36. Wyatt JC, Altman DG (1995) Commentary: Prognostic models: clinically useful or quickly forgotten? BMJ 311:1539-41. 